Article

\title{
Observed Seismic Behavior of a HDRB and SD Isolation System under Far Fault Earthquakes
}

\author{
Antonello Salvatori ${ }^{1}$, Giovanni Bongiovanni ${ }^{2}$, Paolo Clemente ${ }^{2, *}\left(\mathbb{C}\right.$, Chiara Ormando $^{3}\left(\mathbb{C}\right.$, Fernando Saitta ${ }^{2}(\mathbb{)}$ \\ and Federico Scafati ${ }^{1}$ \\ 1 Department of Civil, Construction-Architectural and Environmental Engineering, University of L'Aquila, \\ 67100 L'Aquila, Italy; antonello.salvatori@univaq.it (A.S.); federico.scafati@graduate.univaq.it (F.S.) \\ 2 Italian National Agency for New Technologies, Energy and Sustainable Economic Development, Casaccia \\ Research Centre, 00123 Rome, Italy; giovanni.bongiovldi8@alice.it (G.B.); fernando.saitta@enea.it (F.S.) \\ 3 Department of Civil Engineering and Computer Science Engineering, University of Rome Tor Vergata, \\ 00133 Rome, Italy; chiara.ormando@uniroma2.it \\ * Correspondence: paolo.clemente@enea.it
}

Citation: Salvatori, A.; Bongiovanni, G.; Clemente, P.; Ormando, C.; Saitta, F.; Scafati, F. Observed Seismic Behavior of a HDRB and SD Isolation System under Far Fault Earthquakes. Infrastructures 2022, 7, 13. https: / / doi.org/10.3390/ infrastructures7020013

Academic Editor: Carlo Rainieri

Received: 17 December 2021

Accepted: 17 January 2022

Published: 21 January 2022

Publisher's Note: MDPI stays neutral with regard to jurisdictional claims in published maps and institutional affiliations.

Copyright: (C) 2022 by the authors. Licensee MDPI, Basel, Switzerland. This article is an open access article distributed under the terms and conditions of the Creative Commons Attribution (CC BY) license (https:// creativecommons.org/licenses/by/ $4.0 /)$.

\begin{abstract}
The behavior of a reinforced concrete building, seismically isolated with high damping rubber bearing (HDRB) and sliding devices (SD), observed during the most important events of the seismic sequence that struck central Italy from August 2016 to January 2017, is analyzed. Due to the epicenter distances, all the events had light effects at the site, thus the isolation system was not always put into action. A previous very low energy earthquake and the ambient vibration analysis are used for comparison. The study of the isolation system response is first carried out and the variability of the resonance frequencies with the input energy at the site is pointed out. These frequencies are quite close to those of the superstructure considered as fixed base. Small cracks were observed after the sequence in some partition walls of the building. The analysis of the superstructure was performed by means of a finite element model, assuming a non-linear model for the isolators, based on previous experimental data. The importance of a suitable decoupling between the superstructure and the ground and the contribution of the sliding devices under low energy earthquake is pointed out.
\end{abstract}

Keywords: seismically isolated buildings; base isolation; experimental seismic behavior; high damping rubber bearings; seismic monitoring

\section{Introduction}

Seismic isolation was proposed to mitigate the effects of strong earthquakes in structures. The idea of separating a building from the ground motion was well-known in ancient Greece but the first engineered isolation techniques appeared only in the second half of the nineteenth century [1]. In 1868, Stevenson developed and used in the lighting system in Japan the "aseismatic joint", which consisted of spherical rollers in niches. In 1870 the same idea was used by Touaillon, while Cooper proposed natural-rubber bearings to provide a building with an elastic cushion or a system of springs, and so to mitigate the shocks. The first modern steel-rubber isolators, based on a vulcanization process, were produced in England in the 1970s, while the first curved surface slider, known as friction pendulum, appeared in the USA in the second half of the 1980s [2].

In the usual application in buildings, seismic isolation consists of the insertion of seismic devices between the foundation and the superstructure. The scope is to increase the fundamental period of vibration of a building up to a value for which the acceleration spectral amplitudes are low enough and an elastic behavior of the superstructure is expected under the design earthquake. The energy that the ground transmits to the structure is substantially reduced and so the seismic effects in it $[3,4]$.

Nowadays, the number of buildings protected by seismic isolation is increasing more and more all over the world, also thanks to the good performances of previous applica- 
tions [5], both for new and existing structures [6,7]. Actually, the effectiveness of seismic isolation in preserving structures, included non-structural elements and contents, has been pointed out during several earthquakes [8-16]. The large diffusion of seismic isolation points out the problem of its correct use [17]. The main features, to be accounted for in an optimum preliminary design and check, have been pointed out both for high damping rubber bearings [18-20] and for curved surface sliders [21].

The seismic isolators have a supporting function with reference to vertical loads, both in operating and seismic conditions, and a low horizontal stiffness, to allow relative displacements between the superstructure and the foundation during a seismic event. On the other hand, they must also have an adequate stiffness against horizontal actions of small amplitude, in order to avoid continuous vibrations, which could be dangerous for the building, especially for non-structural elements (due to high frequency vibrations), and cause disturbances to the inhabitants (due to wind or traffic-induced vibrations) [22].

These opposite requirements are not easy to satisfy. In practice, a good isolator should be rigid up to a certain value of the horizontal seismic action but exhibit suitable displacements when this value is overpassed. This threshold should be defined on the basis of the seismic capacity of the superstructure, i.e., its strength under seismic action, assuming a very low behavior factor (preferably equal to 1).

For curved surface sliders the threshold is fixed by the static friction at the onset of motion. Actually, friction is of uncertain evaluation and depends on the vertical load acting during the quake $[23,24]$. Furthermore, it varies during time and could be much higher after a period of inactivity.

In high damping rubber bearings, the shear modulus $G$ increases when the shear strain $\gamma$ diminishes and becomes very high when $\gamma \rightarrow 0$, as pointed out by a previous study in which both the effects on the isolation system [25] and the superstructure were analyzed [26,27].

In this paper the behavior of a reinforce concrete building, seismically isolated by means of HDRBs and SDs, observed during the most important events of the seismic sequence that struck Central Italy from August 2016 to January 2017, is analyzed. Due to the epicenter distances, all the events had light effects at the site. However, small cracks were observed in some partition walls after the main event of 30 October 2016. Obviously, this occurrence did not affect the seismic protection of the structure through seismic isolation. A detailed analysis of the recorded behavior during this earthquake is first shown.

Then, all the considered events are classified on the basis of the accelerations at the basement; their effects, such as accelerations, relative displacements and resonance frequencies are compared. A previous very low energy earthquake and the ambient vibration analysis, when the isolation system was not put in action, are used to analyze the differences in terms of resonance frequencies.

Finally, the analysis of the superstructure was performed by assuming a non-linear model for the isolators, based on previous experimental data. The finite element model first validated using the recordings obtained at the building during the 30 October 2016, Norcia earthquake and used to interpret the experimental behavior.

\section{The Forest Ranger Building and the Monitoring System}

\subsection{The Building and the Isolation System}

The Forest Ranger building of the Umbria Civil Protection Centre in Foligno is a seismically isolated reinforced concrete building (Figure 1). It has an underground level and two floors above the ground. The maximum dimensions in plan are about $16 \times 31 \mathrm{~m}$, in $x$ and $y$ direction, respectively. The inter-floor heights are 3.14, 4.14, and $3.34 \mathrm{~m}$, for the underground, first and second level, respectively. 


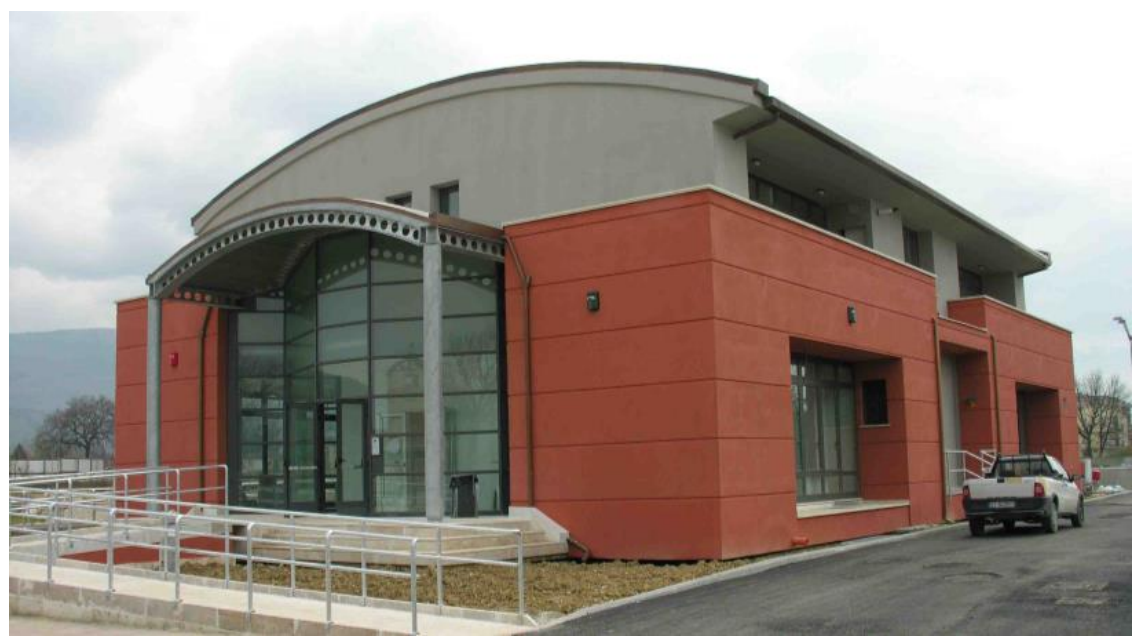

Figure 1. View of the Forest Ranger building (photo P. Clemente).

The isolation system is composed by (Figure 2):

1. 12 HDRBs of Type 1, located along the perimeter of the main rectangular portion;

2. 4 flat slider devices (SD) with a lubricated steel-PTFE (polytetrafluoroethylene) interface, having a nominal friction factor of $1.0 \%$, located at the internal column of the main rectangular portion;

3. 4 HDRBs of Type 2, located at the columns external to the main portion.
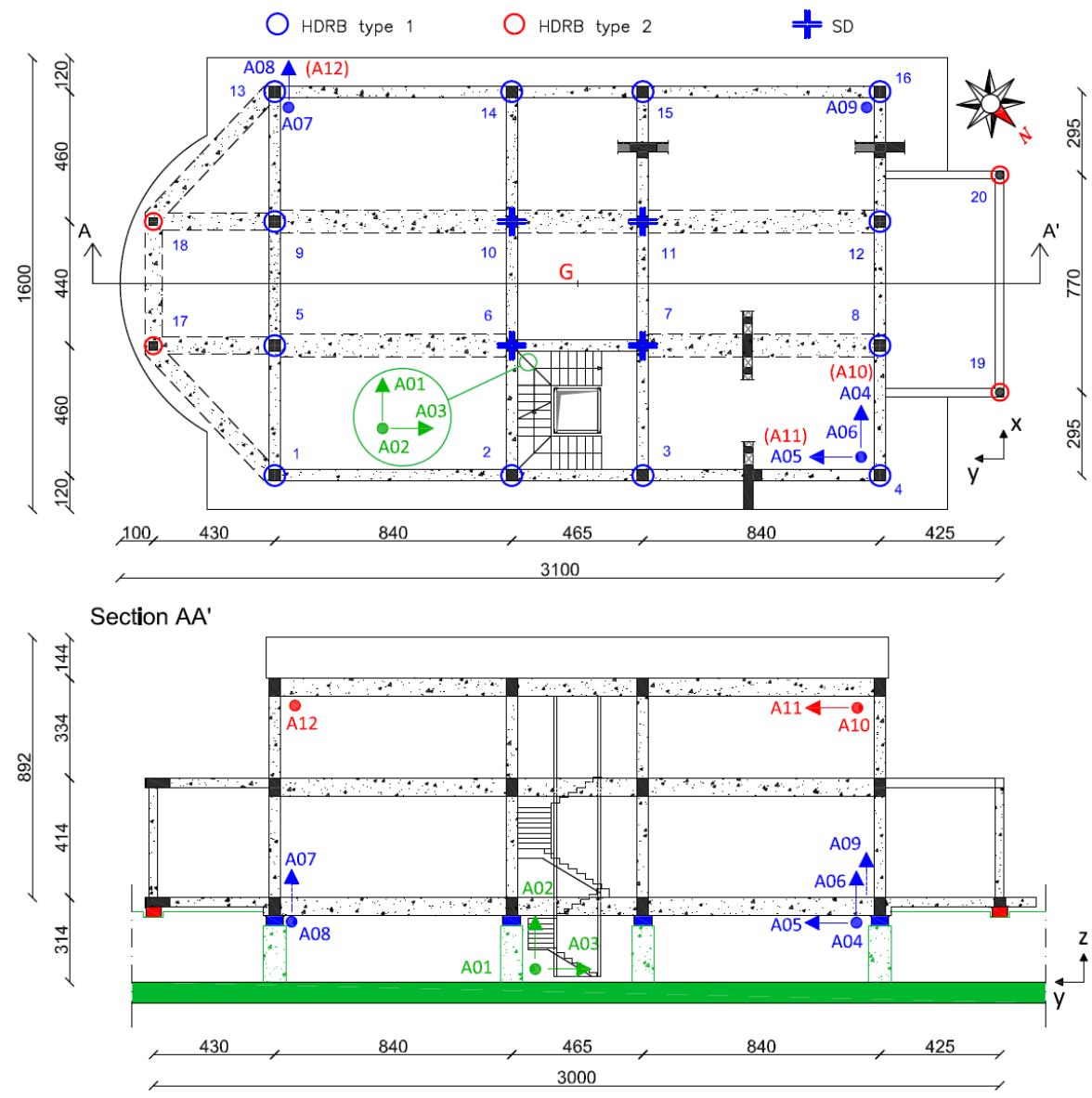

Figure 2. First floor with isolation system and vertical section, with the accelerometers deployment. 
The isolation devices are located at the top of the columns of the underground level. The characteristics of the HDRBs are shown in Table 1. Schematic outlines of the isolators are in Figure 3.

Table 1. Nominal characteristics of the two types of HDRBs.

\begin{tabular}{ccc}
\hline Characteristic & Type 1 & Type 2 \\
\hline Number of devices & 12 & 4 \\
Diameter $(\mathrm{mm})$ & 700 & 550 \\
Total rubber thickness $(\mathrm{mm})$ & 284 & 300 \\
Thickness of a single rubber layer $(\mathrm{mm})$ & 7 & 5 \\
Shear modulus of rubber at $\gamma=1\left(\mathrm{~N} / \mathrm{mm}^{2}\right)$ & 0.4 & 0.4 \\
Equivalent horizontal stiffness at $\gamma=1(\mathrm{~N} / \mathrm{mm})$ & 541 & 317 \\
Equivalent damping factor at $\gamma=1(\%)$ & 10 & 10 \\
Maximum displacement $(\mathrm{mm})$ & 379 & 395 \\
\hline
\end{tabular}

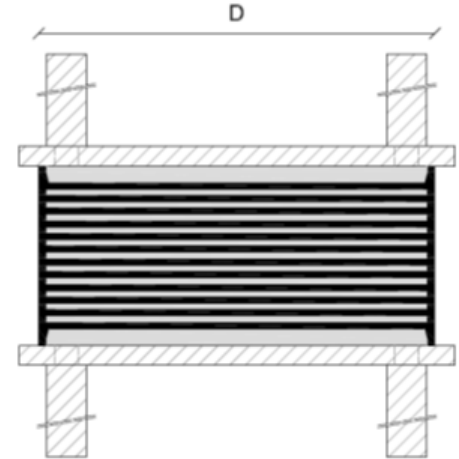

(a)

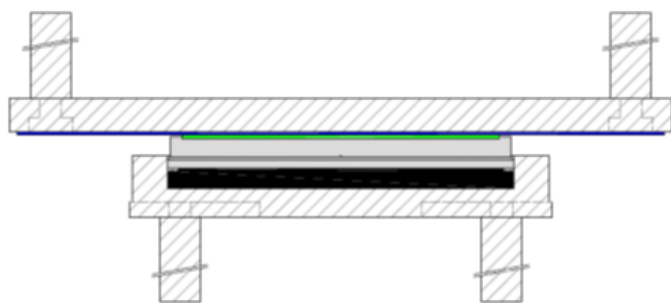

(b)

Figure 3. Schematic sections of (a) an elastomeric isolator and (b) a flat slider device.

The substructure is composed by the foundation beams $(120 \times 75 \mathrm{~cm})$ and 16 columns $(80 \times 80 \mathrm{~cm})$, on which the isolators are placed. The superstructure is a frame structure (columns $40 \times 40 \mathrm{~cm}$, beams $40 \times 64$ or $80 \times 34 \mathrm{~cm}$ ). The floors are reinforced concrete and hollow tiles mixed floors, while the external cornices are in reinforced concrete as well as the stairs between the first floor and the second floor. The elevator shaft is a light steel structure linked to the first, second and covering floors and suspended to them. Additionally, the stairs between the underground and the first floor are in steel and hanged to the elevator steel structure.

The Forest Ranger building was designed following the prescriptions of the technical code in force at the age of the construction [28].

A specific analysis of the seismic hazard, carried out by ENEA, allowed to consider a peak ground acceleration equal to $0.28 \mathrm{~g}$ for a non-exceedance probability of $10 \%$ in 50 years. Based on the results of downhole tests, the subsoil was classified as type B (shear wave velocity between 360 and $800 \mathrm{~m} / \mathrm{s}$ ), for which a soil amplification factor equal to 1.25 was given by the code. Furthermore, with the building being a strategic structure according to the Italian code, the acceleration spectrum ordinates were amplified by an importance factor equal to 1.4. Considering all these amplifications, a peak ground acceleration at the site equal to $0.49 \mathrm{~g}$ was obtained. In Figure 4 the elastic response spectra at the Ultimate limit state (ULS) are shown for two values of the damping factor equal to 5\% and 10\%, respectively. The first value corresponds to the damping associated with the structure; the latter is the value considered in the design phase for the isolation system. 


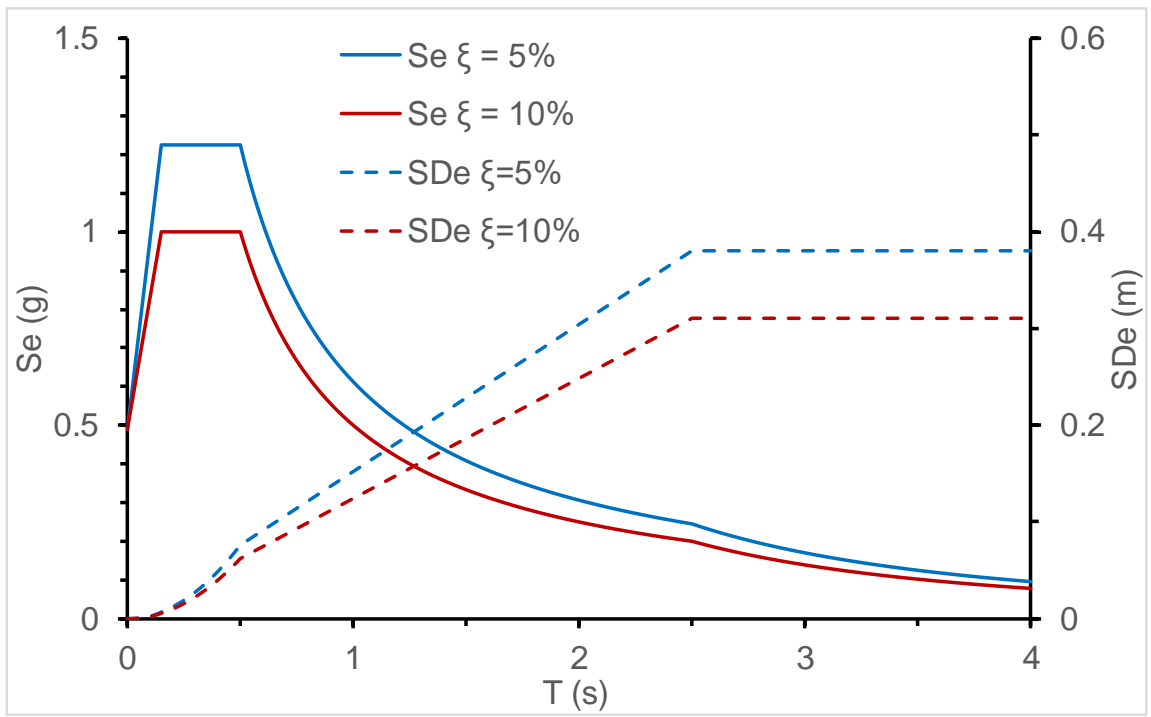

Figure 4. Acceleration spectra (continuous line) and displacement spectra (dotted line) at the ULS.

The design fundamental period of the isolated building was $2.57 \mathrm{~s}$ (fundamental frequency equal to $0.39 \mathrm{~Hz}$ ). According to this value and to a damping factor equal to $10 \%$, the value of the spectral acceleration is $0.19 \mathrm{~g}$, while the value of the spectral displacement is $0.31 \mathrm{~m}$. These values are relative to the initial nominal values of the device characteristics, without aging effects.

\subsection{Behavior under Ambient Vibrations}

The structure was first dynamically characterized using ambient vibrations. For this purpose, a temporary network of 12 velocimeter sensors deployed in the same location of the accelerometers of the permanent network, was used (Figure 2). Data were analyzed in the frequency domain evaluating the power spectral densities (PSD) of all the recording and the cross spectral densities (CDS) of all the significant couples of sensors. The following first three resonance frequencies were extracted by means of the peak picking technique: $3.13 \mathrm{~Hz}, 3.71 \mathrm{~Hz}$ and $3.88 \mathrm{~Hz}$. These resonance frequencies are related to the superstructure modes because the isolation system was not excited by ambient vibrations. The analysis of the phase factors of CSDs allowed to state that the first frequency is associated with a torsional mode, while the second and the third ones are associated with translational modes. They will be compared with the frequencies recorded during the seismic events, in order to check the decoupling of the motion between the superstructure and the ground.

\subsection{The Permanent Accelerometer Network}

The permanent monitoring system is composed by a data acquisition system Kinemetrics K2 and 12 accelerometric sensors Kinemetrics FBA11. The sensors are deployed as follows (Figure 2):

1. Three accelerometers, A01, A02 and A03, are at the basement (level 0, L0) in x, vertical and y direction, respectively;

2. Five accelerometers are on the slab above the isolation interface (level 1, L1), as follows: A04 and A08 in x direction, A05 in y direction, and A06, A07 and A09 in the vertical direction;

3. Three accelerometers are at the top of the building (level 2, L2), as follows: A10 and A12 in $x$ direction and A11 in y direction.

A short term average/long term average (STA/LTA) logic is used to recognize seismic events. The mean value of a signal in a short-time interval of $6 \mathrm{~s}$ is compared with the mean value of the same signal in a long-time interval of $60 \mathrm{~s}$. If the first one is greater than four times the second one, then a trigger command is activated by the sensor. If the 
trigger command is activated simultaneously by at least two sensors at the base and two sensors at the top of the building, the signals are recorded starting from $30 \mathrm{~s}$ before the trigger commands activation. The recording stops $30 \mathrm{~s}$ after the sensors, which activated the trigger command, measure a signal amplitude lesser than the $40 \%$ of the trigger value.

\section{Observed Seismic Behavior}

The permanent monitoring system recorded all the seismic events that struck Central Italy between August 2016 and January 2017. Among these only the most representative earthquakes were chosen to analyze the behavior of the building. The features of the selected earthquakes are summarized in Table 2, where $I_{A}$ represents the Arias intensity at the base of the structure, obtained by the formula $\left(a_{0 x}, a_{0 y}\right.$ and $a_{0 z}$ are the accelerations in the three directions at the basement of the building recorded between the initial time $t_{i}$ and the final time $t_{f}$ of the event) [29]:

$$
I_{A}=\frac{2 \pi}{g} \int_{t_{i}}^{t_{f}}\left[a_{0 x}^{2}(t)+a_{0 y}^{2}(t)+a_{0 z}^{2}(t)\right] d t
$$

Table 2. Data of the selected seismic events.

\begin{tabular}{ccccccc}
\hline Event & Date & $\begin{array}{c}\text { Epicentral } \\
\text { Distance } \mathbf{( k m )}\end{array}$ & $\begin{array}{c}\text { Magnitude } \\
\mathbf{( M w} \text { or } \mathbf{M l})\end{array}$ & Duration D (s) & $\boldsymbol{I}_{\boldsymbol{A}} \mathbf{( \mathbf { c m } / \mathbf { s } )}$ & $\mathbf{I}_{\boldsymbol{A}} / \mathbf{D}\left(\mathbf{c m} / \mathbf{s}^{\mathbf{2}}\right)$ \\
\hline SH008 & 2015.05 .21 & 50 & 3.4 & 9.0 & $2.73 \times 10^{-4}$ & $3.03 \times 10^{-5}$ \\
TX040 & 2016.08 .24 & 53 & 6.0 & 17.3 & 5.19 & $3.00 \times 10^{-1}$ \\
TX053 & 2016.08 .24 & 41 & 5.4 & 15.6 & $5.00 \times 10^{-1}$ & $3.21 \times 10^{-2}$ \\
TX064 & 2016.08 .24 & 59 & 4.1 & 16.3 & $2.02 \times 10^{-3}$ & $1.24 \times 10^{-4}$ \\
TX066 & 2016.08 .24 & 41 & 4.4 & 11.0 & $1.89 \times 10^{-2}$ & $1.72 \times 10^{-3}$ \\
UP036 & 2016.10 .26 & 36 & 5.4 & 10.3 & 2.59 & $2.51 \times 10^{-1}$ \\
UP041 & 2016.10 .26 & 35 & 5.9 & 20.3 & 3.46 & $1.70 \times 10^{-1}$ \\
UP166 & 2016.10 .30 & 36 & 6.5 & 15.8 & 17.5 & 1.11 \\
UR115 & 2017.01 .18 & 68 & 5.5 & 23.0 & $2.25 \times 10^{-1}$ & $9.78 \times 10^{-3}$ \\
\hline
\end{tabular}

In the last column of Table 2, the ratio between $I_{A}$ and the event duration $\mathrm{D}$ is reported, which was evaluated as the time interval between the two instants corresponding to $5 \%$ and $95 \%$ of $I_{A}$, respectively. As one can see, in some cases a greater $I_{A}$ does not correspond to a greater $I_{A} / \mathrm{D}$.

In the following, the behavior recorded during the 30 October 2016, Norcia earthquake, which induced the maximum effects at the site, is carefully analyzed. Then, the results obtain from the selected seismic events are briefly compared to each other.

\subsection{The 30 October 2016 Norcia Earthquake}

The 30 October 2016 Norcia earthquake was the event with the maximum magnitude in the sequence, but also the event that induced the maximum effects at the site of the building. In Figure 5 the acceleration time histories recorded in $\mathrm{x}$ and $\mathrm{y}$ direction, respectively, at the basement L0 (A01 and A03), at the first floor above the isolation interface L1 (A04 and A05) and at the top of the building L2 (A10 and A11) are plotted. The peaks of the acceleration, for the same levels, are PBA $=0.098 \mathrm{~g}$, PIA $=0.054 \mathrm{~g}$ and PTA $=0.059 \mathrm{~g}$, respectively. The absence of amplification from the basement to the top, which characterizes isolated structures, is clearly recognizable. On the contrary, there is a reduction in acceleration between the basement (L0) and the first floor above the isolation system (L1). 


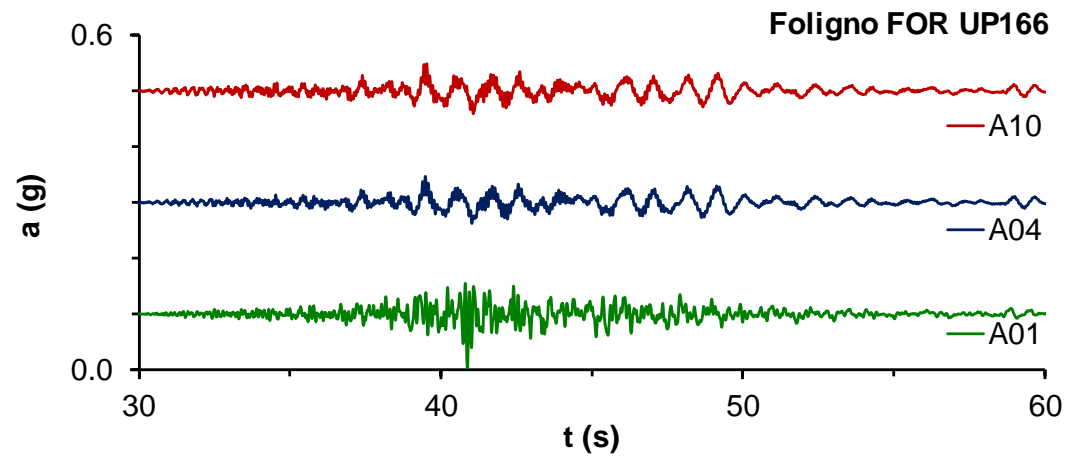

(a)

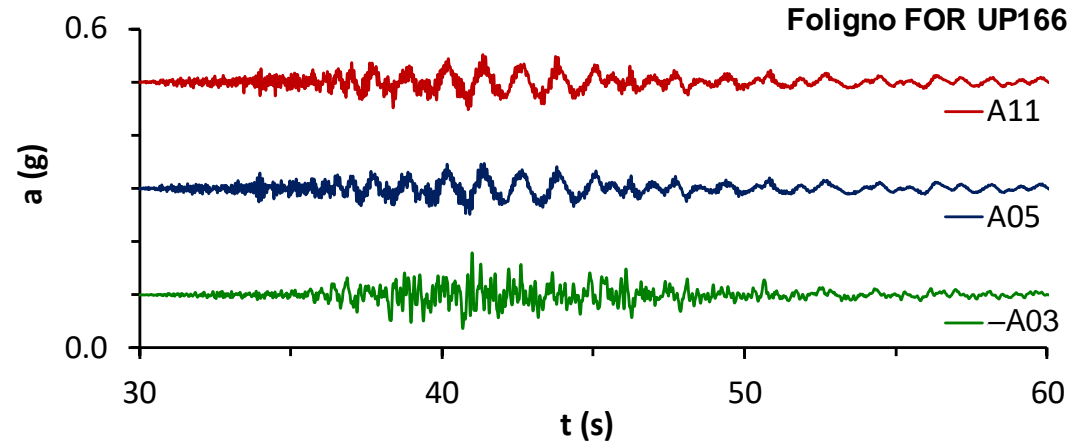

(b)

Figure 5. Time histories at the basement (green), at the first floor above the isolation system (blue) and at the top of the building (red) during the 30 October 2016, Norcia earthquake in (a) $x$ direction and (b) y direction (the sign of record at A03 has been changed; therefore, it is named -A03 in the legend).

The Fourier spectra for the horizontal sensors are plotted in Figure 6. The sensors in the same direction, deployed in the superstructure, show a peak of amplitude for the same frequency, equal to $0.95 \mathrm{~Hz}$ in $\mathrm{x}$ direction and $0.81 \mathrm{~Hz}$ in y direction. These resonance frequencies are much lower than the resonance frequencies recorded under ambient vibrations and related to the superstructure. The spectrum rotates of the recordings obtained at the couples A04-A05 and A10-A11 confirmed the presence of two different frequencies along the two main directions (Figure 7).

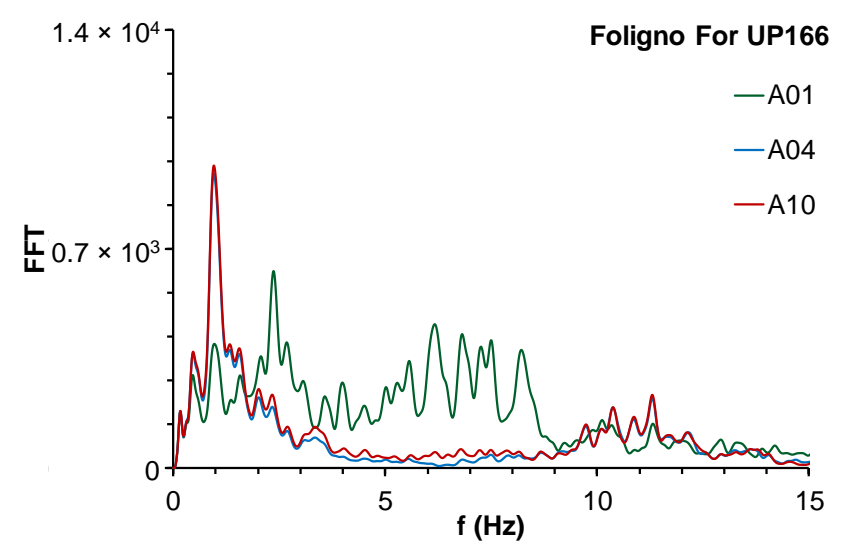

(a)

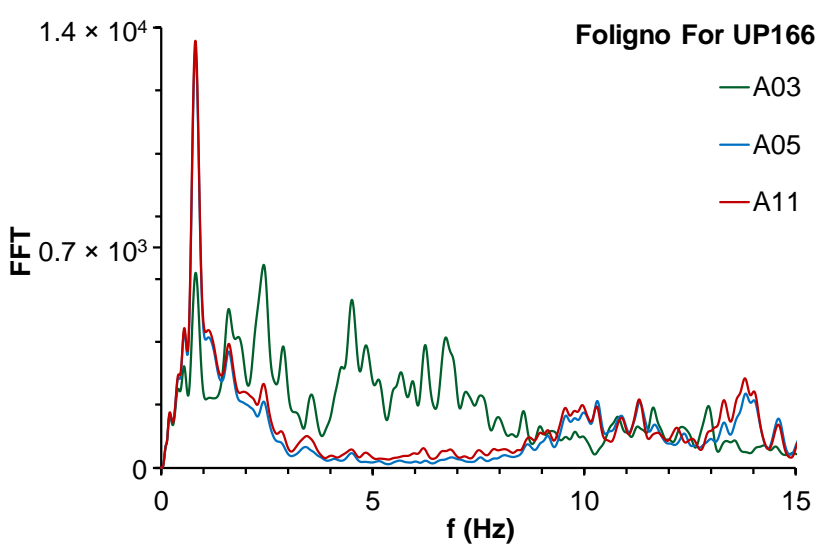

(b)

Figure 6. Fourier spectrum amplitude at different levels obtained during the 30 October 2016 Norcia Earthquake in (a) $\mathrm{x}$ direction and (b) y direction. 

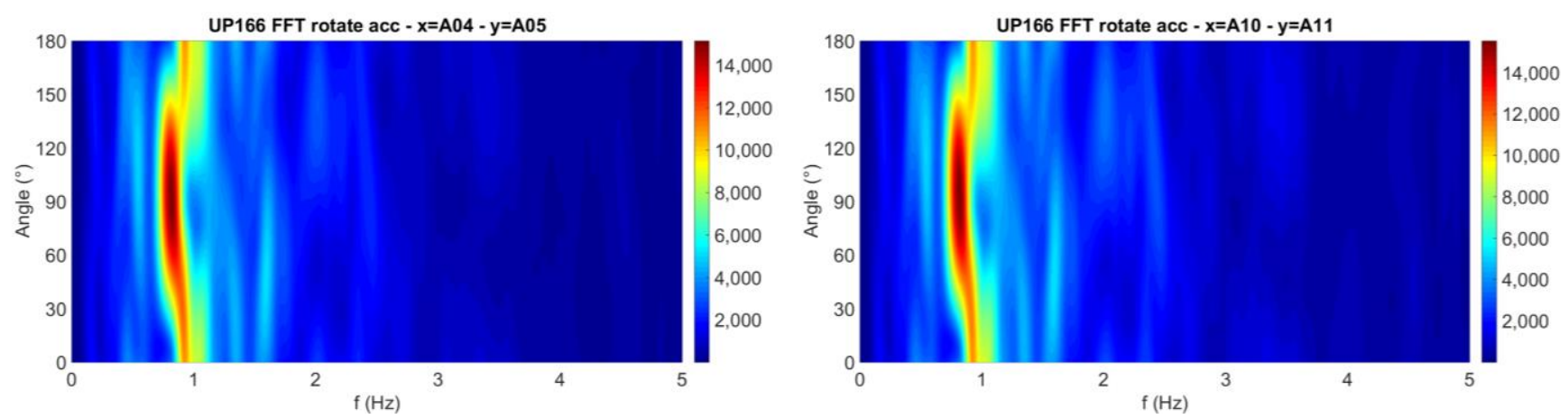

Figure 7. Spectrum rotates of the couples of recordings A04-A05 and A10-A11, obtained during the 30 October 2016 Norcia earthquake.

The presence of two different resonance frequencies in the two directions could be related to a non-perfect symmetry of the isolation system. The wavelet transforms [30], plotted in Figure 8 for sensors A10 and A11, show that the dominant frequencies vary during the seismic event and the frequencies related to the isolation system are particularly evident only during a small portion of the time histories. One can deduce that the resonance frequencies changed during the earthquake and that the isolation system did not work for the entire recording. These occurrences justify the presence of more peaks in the spectra around the resonance frequency. Furthermore, between $46 \mathrm{~s}$ and $50 \mathrm{~s}$, vibrations prevail in $x$ direction.

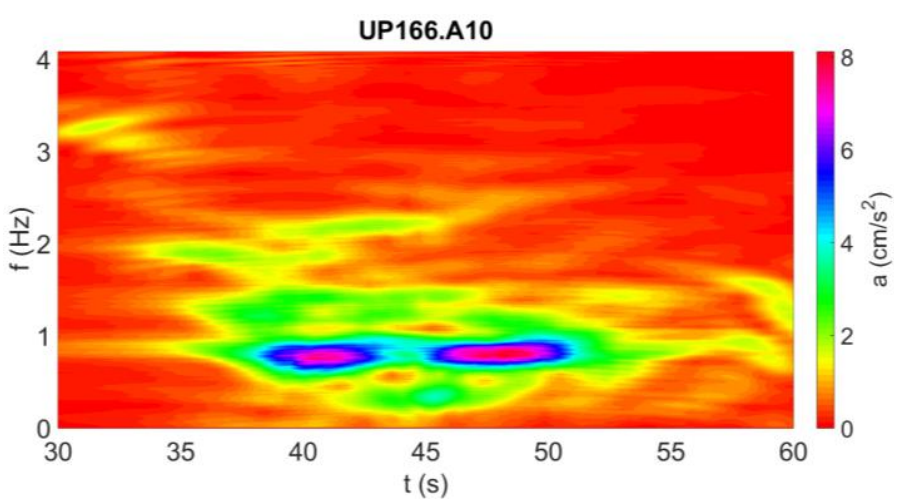

(a)

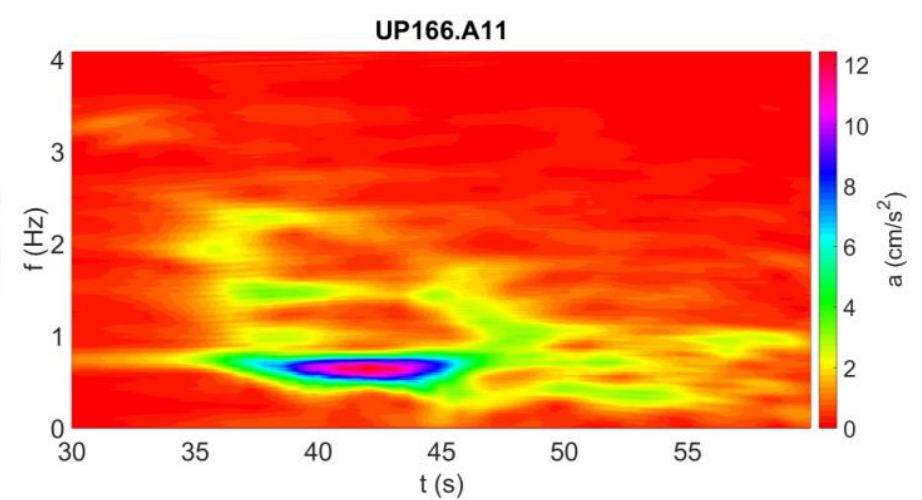

(b)

Figure 8. Time-frequency analysis for (a) A10 and (b) A11.

Other peaks are likely due to the change of the dominant frequency of the earthquake during the event.

In Figure 9, the cross spectral densities (CSD), plotted in terms of amplitude and phase factor, and the corresponding coherence functions between sensors in $\mathrm{x}$ direction at the different levels (L0 and L1, L1 and L2) and between parallel sensors at the same level are shown. The CSDs of sensors in y direction are plotted in Figure 10. The analysis of the CSDs show that in correspondence of the already pointed out frequencies, the coherence function is always close to one. Furthermore, the values of the phase factor are equal to zero both for couples of sensors placed at different levels and couples of sensors placed at the same level (for $x$ direction). So, it appears that the superstructure moves as a rigid body and the first fundamental modes are translational modes. 

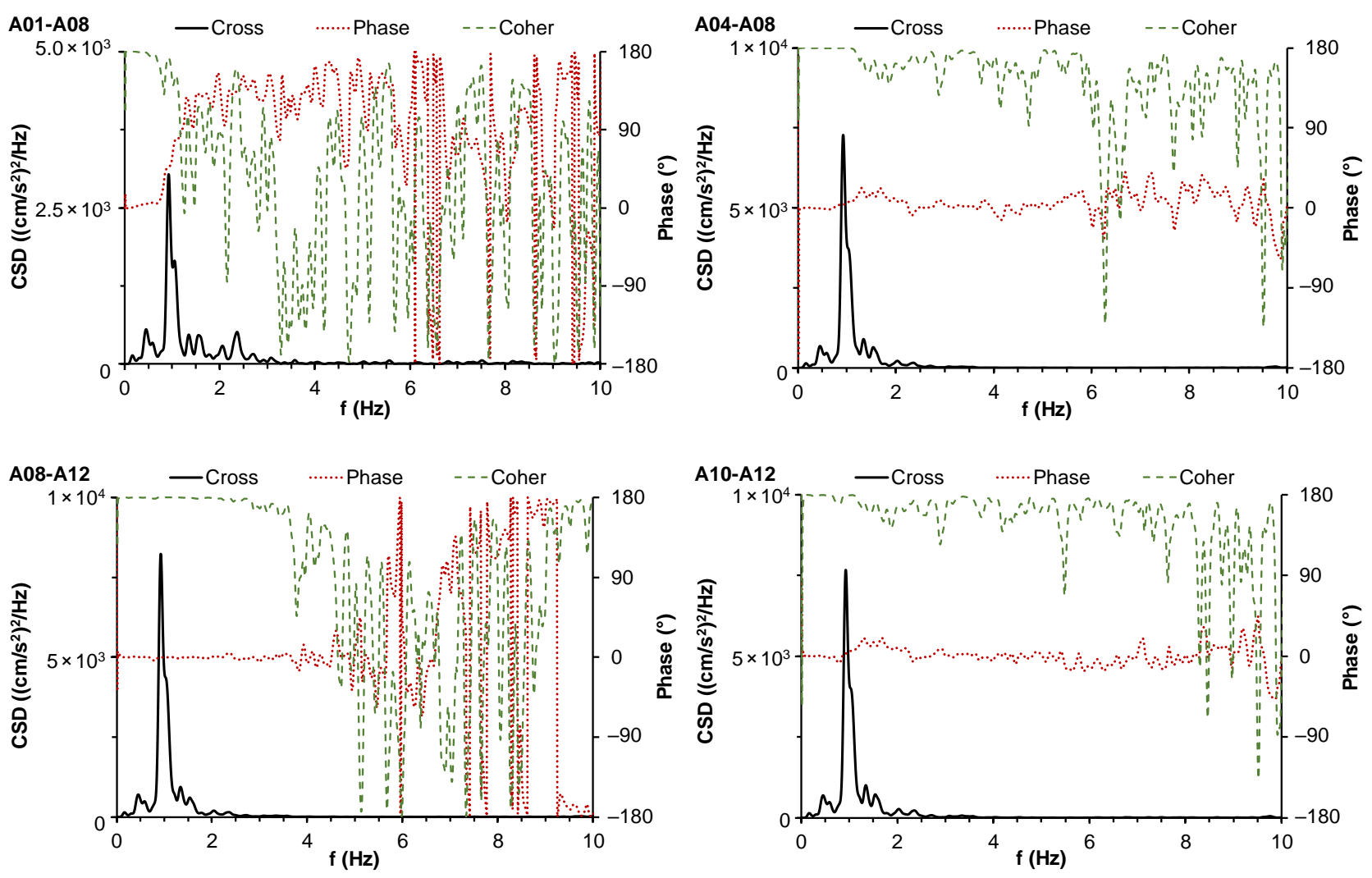

(a)

(b)

Figure 9. CSD of sensors in $x$ direction (a) at different levels and (b) at the same level (the coherence varies in $[0,1])$.
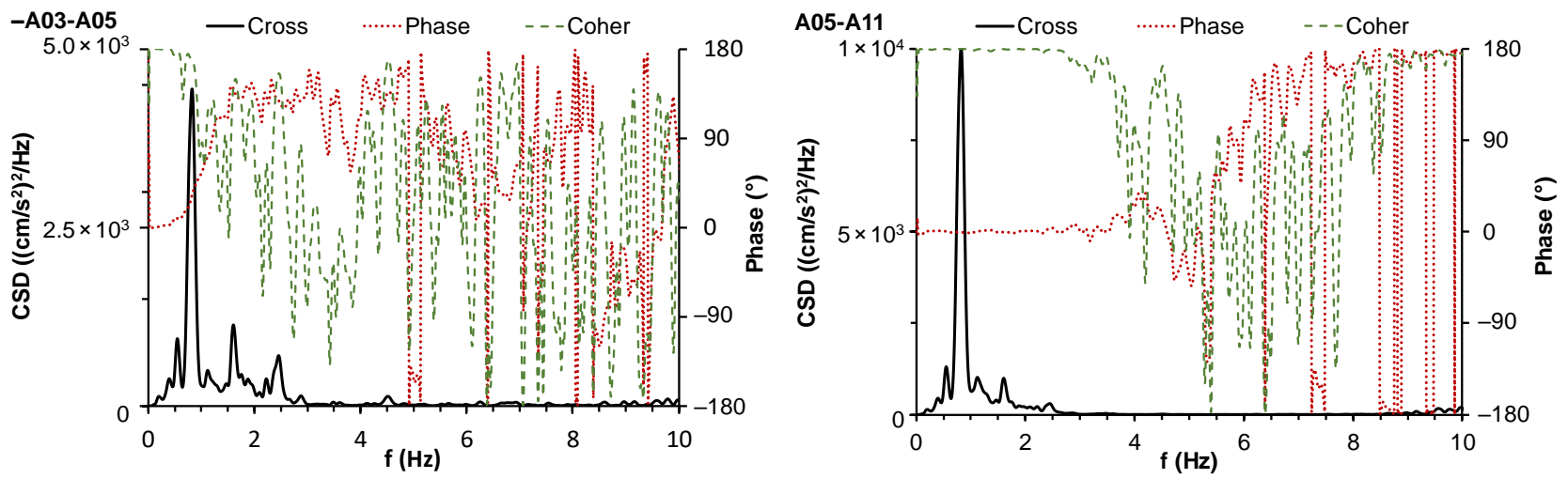

Figure 10. CSD of sensors in y direction at different levels (the coherence varies in $[0,1]$ ).

By means of a double integration in the frequency domain, the time histories of the displacements (Figure 11) were obtained from the acceleration time histories. The maximum values of the horizontal displacements of the gravity centers at L0, L1 and L2 were $27.3,31.8$ and $32.0 \mathrm{~mm}$, respectively. 


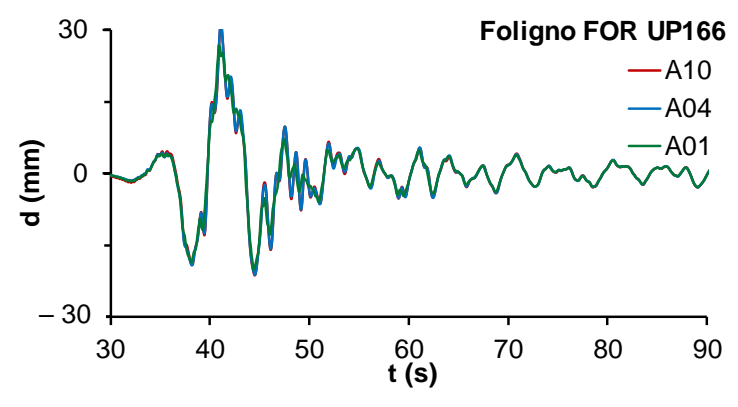

(a)

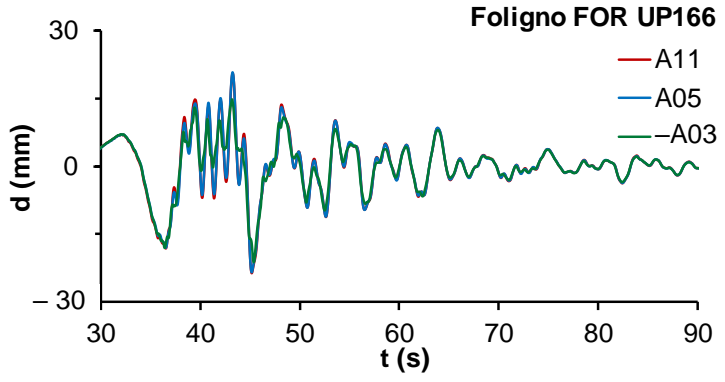

(b)

Figure 11. Time histories of the absolute displacements at different level in (a) $x$ direction (b) $y$ direction (the sign of record at A03 has been changed; therefore, it is named -A03 in the legend).

The relative horizontal displacements between L1 and L0, and between L2 and L1 were obtained for the 4 corner points, which correspond to the position of the isolation devices Is01, Is04, Is13 and Is16. The relative particle motions of these points are plotted in Figure 12, while the maximum values are summarized in Table 3. As one can see, the maximum displacement of the building does not exceed $32 \mathrm{~mm}$.

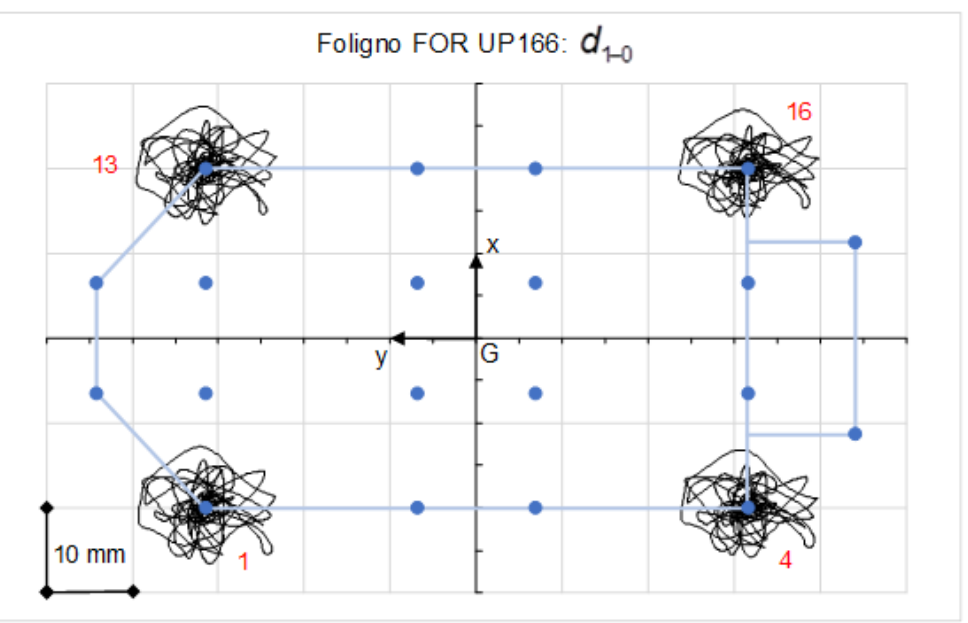

(a)

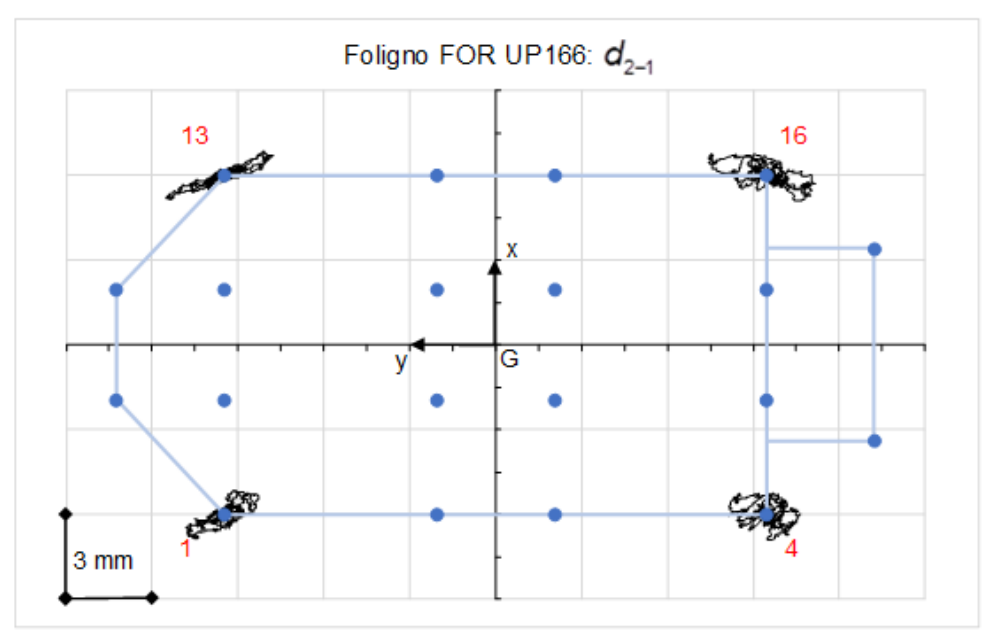

(b)

Figure 12. Relative particle motions at the points corresponding to the position of the corner isolation devices between (a) L1 and L0, and (b) L2 and L1. 
Table 3. Maximum relative displacement $\mathrm{d}_{1-0}$ between $\mathrm{L} 1$ and $\mathrm{L} 0$, and $\mathrm{d}_{2-1}$ between $\mathrm{L} 2$ and $\mathrm{L} 1$, at the points corresponding to the position of the corner isolation devices.

\begin{tabular}{ccccc}
\hline Isolator & Is01 & Is04 & Is13 & Is16 \\
\hline $\mathrm{d}_{1-0}(\mathrm{~mm})$ & 9.28 & 8.80 & 8.81 & 8.38 \\
$\mathrm{~d}_{2-1}(\mathrm{~mm})$ & 1.49 & 1.35 & 2.19 & 2.12 \\
\hline
\end{tabular}

The superstructure has a maximum relative displacement of about $2.2 \mathrm{~mm}$ between L2 and L1. This value is much lower than the limit value allowed by the Italian technical code at the serviceable limit state for strategic seismic isolated buildings, which is equal to h/450, $\mathrm{h}$ being the inter-story height. The displacement is concentrated at the level of the isolation system, where the maximum relative displacement in the isolation devices is about $9.3 \mathrm{~mm}$, corresponding to a shear strain of 0.033 . In Figure $12 \mathrm{~b}$ it is clearly recognizable the rotation of the top of the building, with respect to L1, around a point external with respect to the building plan.

\subsection{Comparison of the Structure Behavior under Different Seismic Events}

In Figure 13 the magnitudes of the different events are plotted versus the epicenter distance, for the selected events listed in Table 2. The sizes of the circles are proportional to the Arias intensity but are not representative for events with $M<5$. The influence of the magnitude and the epicenter distance on the Arias intensity is apparent.

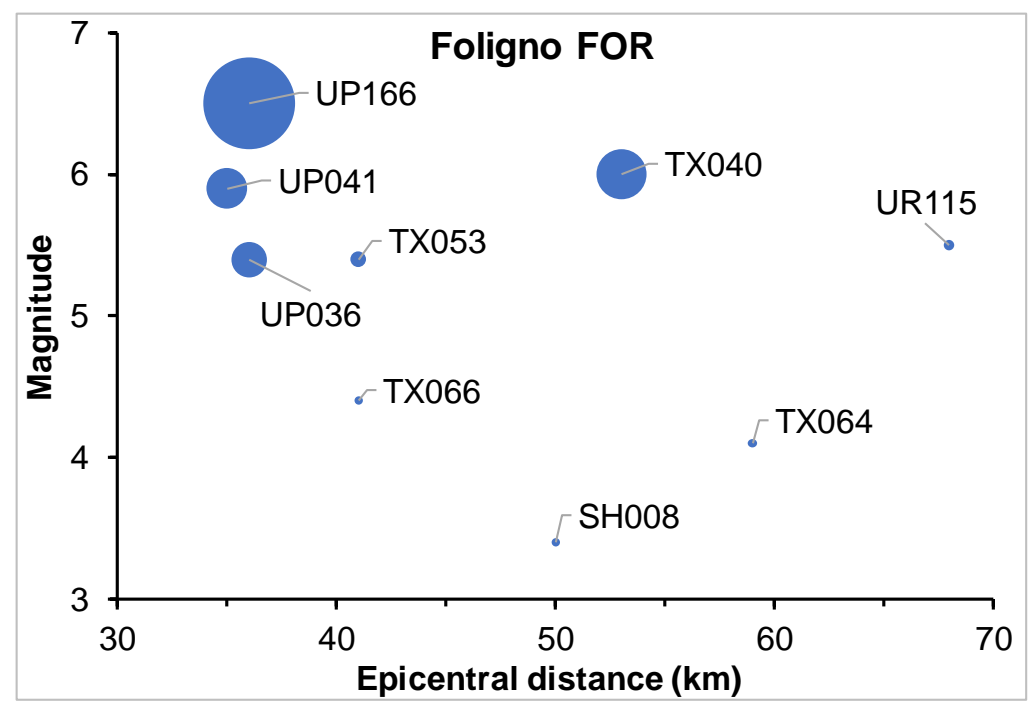

Figure 13. Magnitude versus epicenter distance for the recorded events. The areas of the circles are proportional to $I_{A}$, except for events with $\mathrm{M}<5$.

In Figure 14, the maximum accelerations in $\mathrm{x}$ and $\mathrm{y}$ direction occurred at L0 (A01 and A03), L1 (A04 and A05) and L2 (A10 and A11), respectively, and are plotted versus $I_{A}$ for all the recorded seismic events. Both the horizontal components of the accelerations at the three levels increase with $I_{A}$. The acceleration at the basement (PBA) is not always greater than the acceleration at L1 and L2, as shown also in Figure 15, where the maximum accelerations, obtained as vector sum of the components along $\mathrm{x}$ and $\mathrm{y}$, are shown. However, the structural amplification in these cases is quite low. It is worth pointing out also that PBA does not always increase with $I_{A}$. In some cases, this occurrence can be justified by means of $I_{A} / \mathrm{D}$ ratio (UP036, see Table 2), in other cases by the presence of a very high peak in the acceleration time history. 

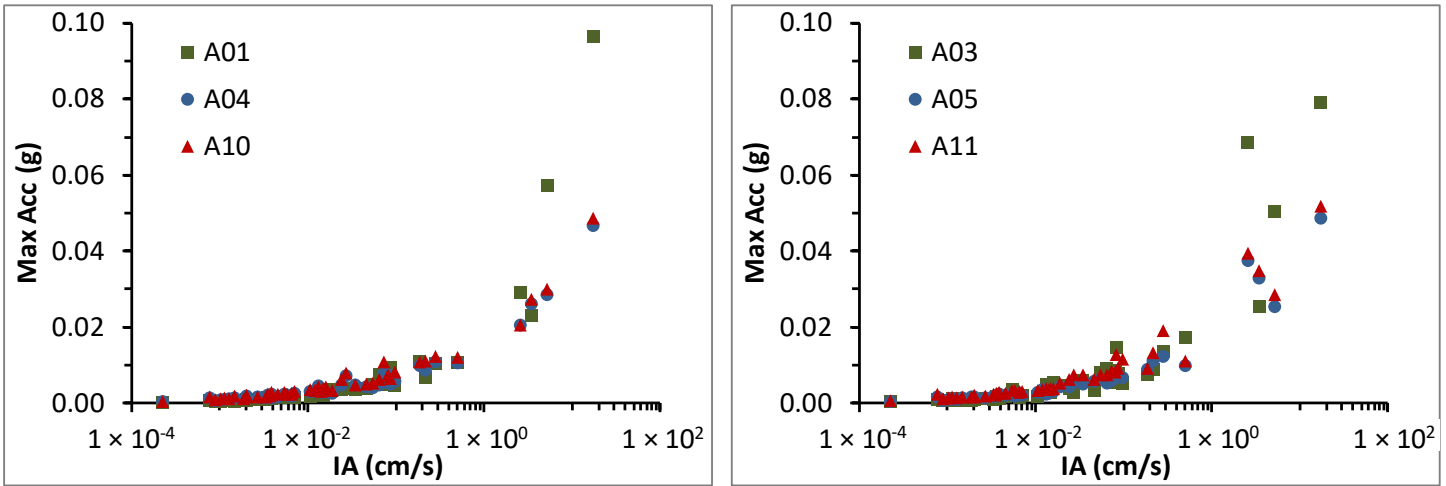

Figure 14. Maximum absolute acceleration at the basement PBA (A01 and A03 in $\mathrm{x}$ and y direction, respectively), above the isolation system PIA (A04 and A05), and at the top of the building PTA (A10 and A11), for all the recorded seismic events.

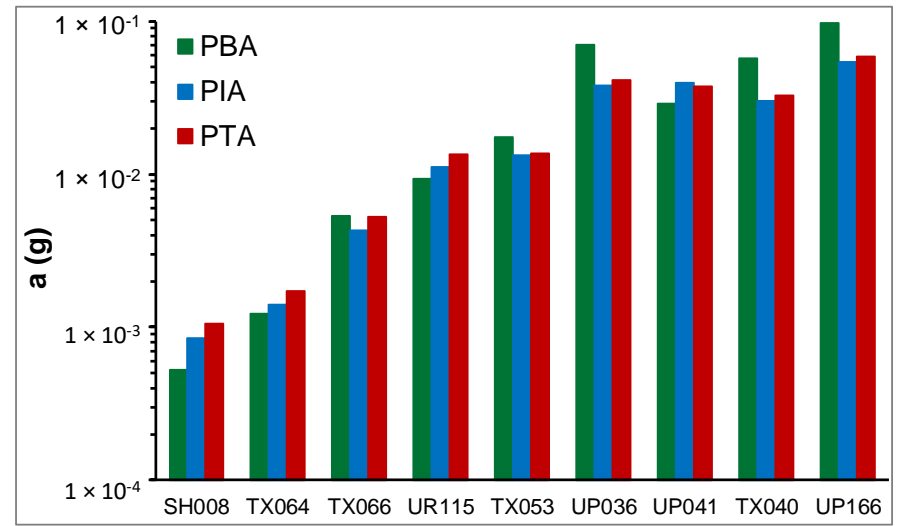

Figure 15. Maximum absolute acceleration at the basement PBA, above the isolation system PIA and at the top of the building PTA for the selected seismic events.

In Figures 16 and 17, the maximum absolute displacements at the three levels and the relative displacements $\mathrm{d}_{1-0}$, between the gravity centers of $\mathrm{L} 1$ and $\mathrm{L} 0$, and $\mathrm{d}_{2-1}$, between the gravity centers of $\mathrm{L} 2$ and $\mathrm{L} 1$, are shown in increasing order of $I_{A}$. The displacement at the basement does not increase always with $I_{A}$ and the maximum displacement does not occur always at the top of the building. As already pointed out, this occurrence can be justified with a different $\mathrm{D}$ or the presence of a very high peak in the time history. Instead, the relative displacement $\mathrm{d}_{1-0}$ is always higher than $\mathrm{d}_{2-1}$, also for the lowest energy earthquakes. Acceleration and displacement values are synthesized in Table 4.

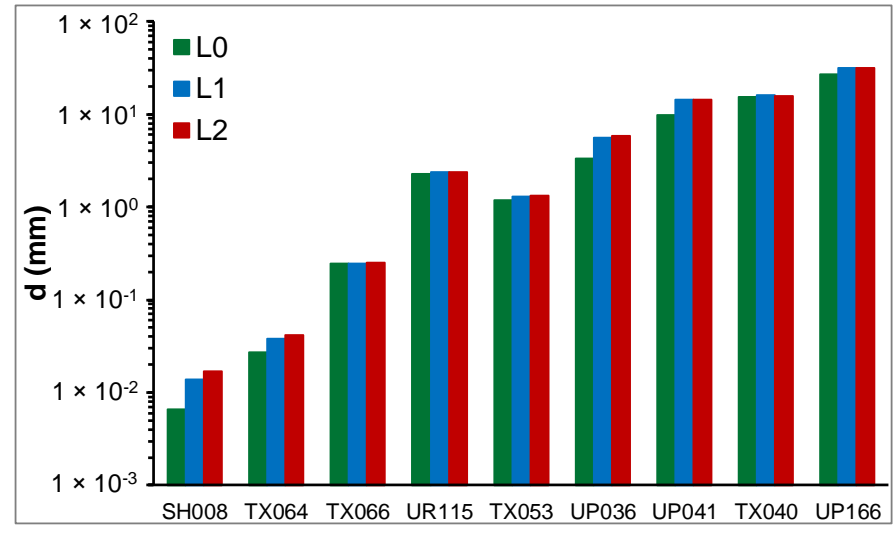

Figure 16. Maximum absolute displacement between the gravity centers at L0, L1 and L2 for the considered seismic events. 


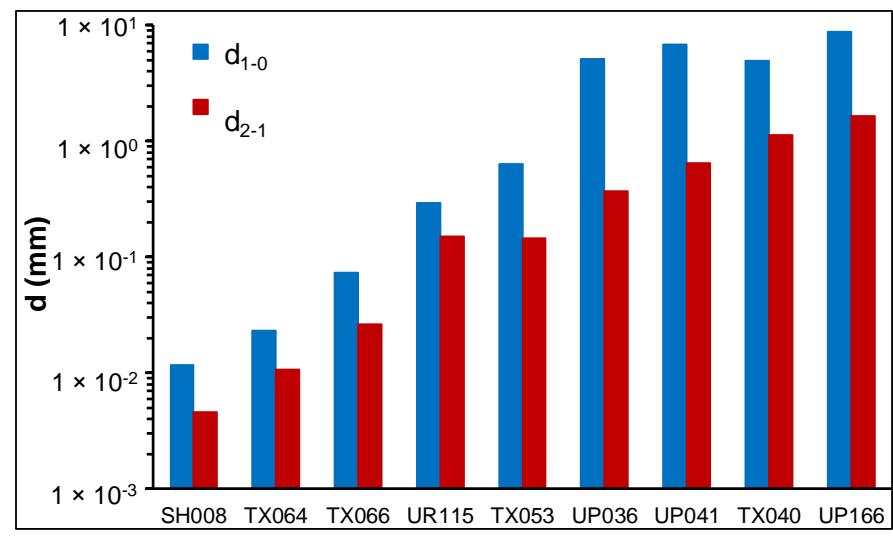

Figure 17. Maximum relative displacement between the gravity centers at L1 and L0, and at L2 and L1, for the considered seismic events.

Table 4. Maximum accelerations, displacements, relative displacements of the gravity centers and maximum relative displacements at the corner isolators for the selected seismic events.

\begin{tabular}{|c|c|c|c|c|c|c|c|c|c|}
\hline Event & SH008 & TX064 & TX066 & UR115 & TX053 & UP036 & UP041 & TX040 & UP166 \\
\hline PBA (g) & 0.0005 & 0.0012 & 0.0054 & 0.0094 & 0.0175 & 0.0706 & 0.0291 & 0.0575 & 0.0975 \\
\hline PIA (g) & 0.0008 & 0.0014 & 0.0043 & 0.0111 & 0.0134 & 0.0379 & 0.0397 & 0.0300 & 0.0539 \\
\hline PTA (g) & 0.0011 & 0.0017 & 0.0053 & 0.0136 & 0.0136 & 0.0411 & 0.0373 & 0.0327 & 0.0589 \\
\hline PBD (mm) & 0.0066 & 0.0271 & 0.2439 & 2.2917 & 1.1813 & 3.3642 & 9.7588 & 15.415 & 27.302 \\
\hline $\operatorname{PID}(\mathrm{mm})$ & 0.0138 & 0.0378 & 0.2467 & 2.3663 & 1.3072 & 5.5737 & 14.443 & 16.213 & 31.809 \\
\hline PTD (mm) & 0.0171 & 0.0417 & 0.2524 & 2.3821 & 1.3349 & 5.8568 & 14.367 & 15.765 & 31.956 \\
\hline $\mathrm{d}_{1-0}(\mathrm{~mm})$ & 0.0116 & 0.0230 & 0.0728 & 0.2907 & 0.6282 & 5.0766 & 6.7810 & 4.9572 & 8.7882 \\
\hline $\mathrm{d}_{2-1}(\mathrm{~mm})$ & 0.0046 & 0.0107 & 0.0261 & 0.1503 & 0.1453 & 0.3685 & 0.6432 & 1.1301 & 1.6426 \\
\hline $\begin{array}{l}\mathrm{d}_{1-0} \mathrm{Is} 01 \\
(\mathrm{~mm})\end{array}$ & 0.0116 & 0.0224 & 0.0744 & 0.2869 & 0.6686 & 5.0513 & 6.6656 & 5.2281 & 9.2833 \\
\hline $\begin{array}{c}\mathrm{d}_{1-0} \mathrm{Is} 04 \\
(\mathrm{~mm})\end{array}$ & 0.0142 & 0.0236 & 0.0727 & 0.2847 & 0.6206 & 5.0211 & 6.7040 & 4.7085 & 8.7999 \\
\hline $\begin{array}{c}\mathrm{d}_{1-0} \mathrm{Is} 13 \\
(\mathrm{~mm})\end{array}$ & 0.0114 & 0.0234 & 0.0730 & 0.2968 & 0.6384 & 5.1327 & 6.8636 & 5.2482 & 8.8119 \\
\hline $\begin{array}{c}\mathrm{d}_{1-0} \mathrm{Is} 16 \\
(\mathrm{~mm})\end{array}$ & 0.0149 & 0.0251 & 0.0738 & 0.2947 & 0.5880 & 5.1030 & 6.9015 & 4.7466 & 8.3750 \\
\hline $\begin{array}{c}\mathrm{d}_{2-1} \mathrm{Is} 01 \\
(\mathrm{~mm})\end{array}$ & 0.0045 & 0.0107 & 0.0279 & 0.1439 & 0.1424 & 0.4136 & 0.5993 & 0.9671 & 1.4852 \\
\hline $\begin{array}{c}\mathrm{d}_{2-1} \mathrm{Is} 04 \\
(\mathrm{~mm})\end{array}$ & 0.0046 & 0.0111 & 0.0292 & 0.1385 & 0.1310 & 0.4408 & 0.5747 & 0.9542 & 1.3457 \\
\hline $\begin{array}{l}\mathrm{d}_{2-1} \mathrm{Is} 13 \\
(\mathrm{~mm})\end{array}$ & 0.0047 & 0.0113 & 0.0272 & 0.1735 & 0.1680 & 0.3127 & 0.7596 & 1.5602 & 2.1928 \\
\hline $\begin{array}{l}\mathrm{d}_{2-1} \mathrm{Is} 16 \\
(\mathrm{~mm})\end{array}$ & 0.0049 & 0.0109 & 0.0264 & 0.1631 & 0.1531 & 0.3454 & 0.7973 & 1.5626 & 2.1249 \\
\hline
\end{tabular}

For all the recorded events a frequency domain analysis was performed. In Figure 18 the first two resonance frequencies are plotted versus $I_{A}$. As one can see, in a lower energy range, the resonance frequency is independent of the seismic energy and varies in a small range around the value related to the superstructure. In these cases, the isolation system was not activated probably because of the friction forces of the SDs. For higher values of $I_{A}$, instead, the seismic isolation system was put in action and the first resonance frequencies, related to the isolation system, decrease almost linearly with $\log \left(I_{A}\right)$. As one can see, for low energy earthquakes the resonance frequencies approach those of the superstructure and there was no decoupling of motion. 


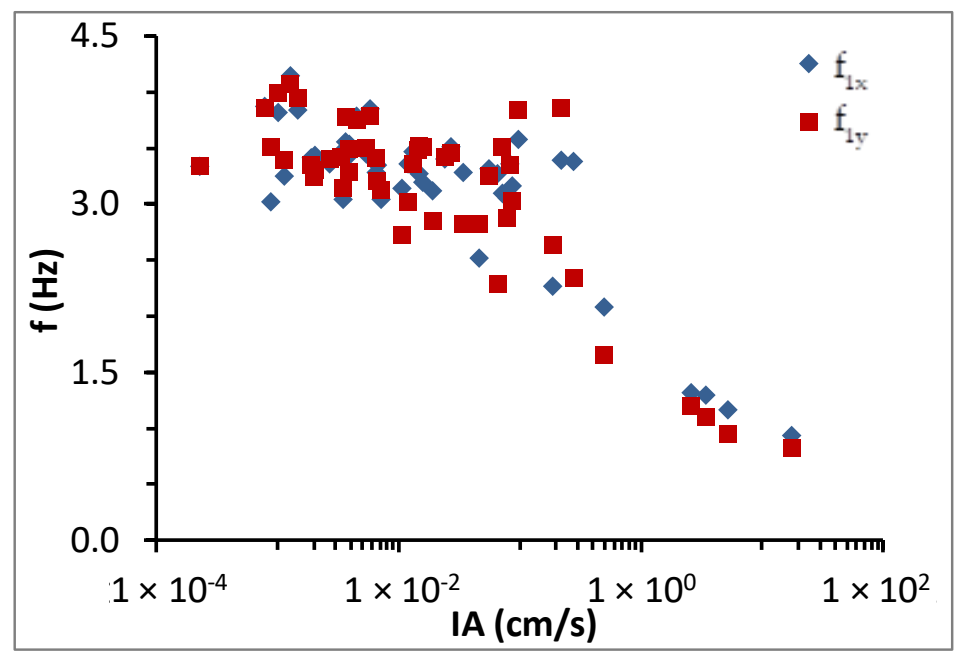

Figure 18. First resonance frequencies versus $I_{A}$ for all the recorded seismic events.

\section{Non-Linear Modelling of the Isolation System}

The design frequency of the structure is $0.39 \mathrm{~Hz}$, while during the seismic events in which the isolation system was activated, the resonance frequency varies between $0.8 \mathrm{~Hz}$ and $2.5 \mathrm{~Hz}$. This effect is to be related to the change of the stiffness of the isolation devices, which depends on the angular strain.

A suitable model to represents this behavior was set up with reference to another building, seismically isolated with HDRBs produced by the same manufacturer, which is also part of the Civil Protection Centre at Foligno [27]. The devices used for the type tests at time of construction, and properly conserved, were subjected to the displacement time history obtained in the devices on site during the 30 October 2016 Norcia earthquake. In the force-displacement diagram, several cycles were selected. Each of them was approximated by an elliptical curve with center in the origin and, with reference to this ellipse, the equivalent stiffness and viscous damping were calculated.

As usual, in the type tests the devices were subject to six sets of five sinusoidal cycles, each set having the same frequency of $0.5 \mathrm{~Hz}$ but different amplitudes (corresponding to $\gamma$ $=0.05,0.30,0.50,0.70,1.00$ and 2.00), keeping an axial pressure of $6.0 \mathrm{~N} / \mathrm{mm}^{2}$. These tests allowed to obtain the shear modulus and the equivalent viscous damping of the isolation devices for $\gamma=0.05 \div 2.00$. The additional test, with the seismic recorded time histories, gave the values of $G$ for $\gamma<0.05$.

The procedure used and the results of all these tests are extensively described in previous papers, in which a very simple formulation was also proposed to relate the shear modulus and the damping factor to the shear strain [27]:

$$
\begin{gathered}
G=G_{1} \gamma^{-0.43} \\
\xi=\xi_{1} \gamma^{-0.6}
\end{gathered}
$$

where $\gamma$ is the shear modulus and $G_{1}=0.4 \mathrm{~N} / \mathrm{mm}^{2}$ and $\xi_{1}=10 \%$ are the shear modulus and the damping factor corresponding to $\gamma=1$, respectively.

From Equation (2), the relation between the horizontal force $F$ and the shear modulus can be obtained [27]:

$$
F=G_{1} A \gamma^{0.57}
$$

where $A$ is the area of the cross section of the isolation device. In Figure 19, the horizontal force and the shear modulus are plotted versus the shear strain. 


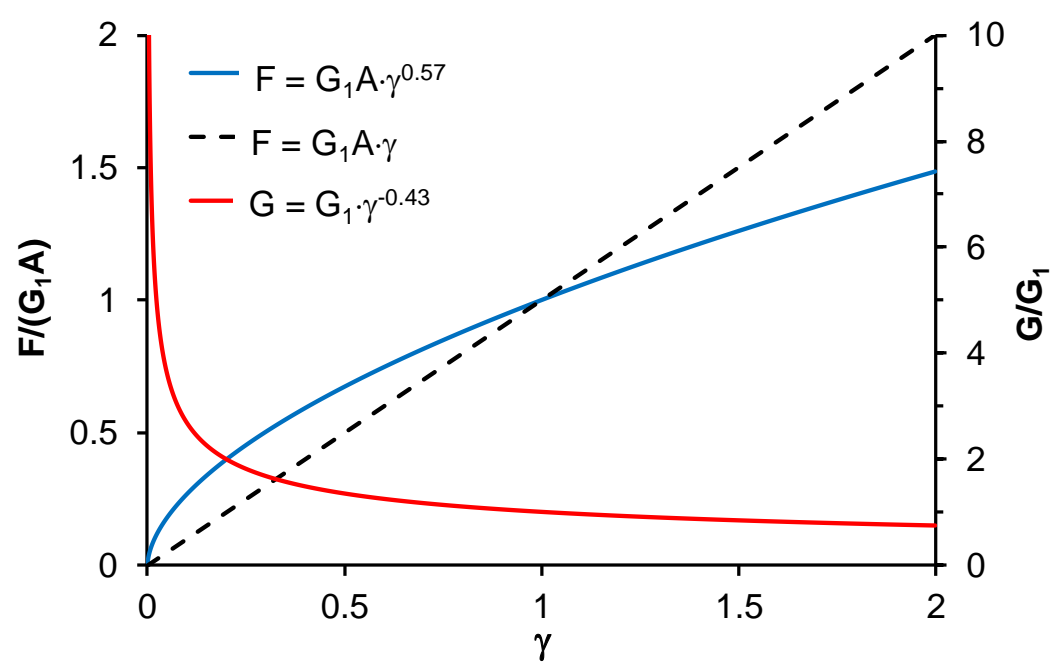

Figure 19. Force and shear modulus versus the shear strain.

\section{Comparison between the Observed Behavior and the Numerical Analysis}

Using the software Midas Gen, a finite-element model of the superstructure was set up to compare the experimental results with the numerical ones. The numerical model was set up on the basis on the design documents. Only frame elements were used to model the structural elements, while the floors and the slabs were considered only as a permanent weight.

The structure was subjected to the self-weight of the structural elements, the additional permanent loads and a percentage of the variable loads, which were likely present during the seismic events. The assumed values are listed in Table 5.

Table 5. Self-weight, permanent loads and variable load in seismic conditions.

\begin{tabular}{|c|c|c|c|c|}
\hline Floor & $\begin{array}{l}\text { Self-Weight } \\
\left(\mathrm{kN} / \mathrm{m}^{2}\right)\end{array}$ & $\begin{array}{l}\text { Permanent Load } \\
\qquad\left(\mathrm{kN} / \mathrm{m}^{2}\right)\end{array}$ & $\begin{array}{l}\text { Partition Walls } \\
\left(\mathrm{kN} / \mathrm{m}^{2}\right)\end{array}$ & $\begin{array}{l}\text { Variable Load } \\
\qquad\left(\mathrm{kN} / \mathrm{m}^{2}\right)\end{array}$ \\
\hline First & 4.0 & 2.4 & 0.8 & 0.60 \\
\hline Second & 4.0 & 4.9 & 0.8 & 0.60 \\
\hline Third & 4.0 & 2.7 & 0.0 & 0.00 \\
\hline
\end{tabular}

The isolation devices were modelled by means of elastic link elements, assigning a linear behavior. The effects of aging were accounted for increasing the shear modulus of the rubber by $15 \%\left(\mathrm{G}_{1 \mathrm{a}}=1.15 \times \mathrm{G}_{1}=0.46 \mathrm{~N} / \mathrm{mm}^{2}\right)$ [31,32]. Actually, about 12 years have passed from the construction of the building to the seismic events.

In Table 6, the results of the modal analysis are shown. The first period is equal to $2.55 \mathrm{~s}$ (frequency of $0.39 \mathrm{~Hz}$ ), which is very close to that assumed in the design phase. The first two modal shapes are translational, while the third one is torsional. The higher frequencies are related to the superstructures and are a little lower than those obtained from the ambient vibration analysis. This occurrence can be related to the contribution of the non-structural elements during the ambient vibration tests.

Table 6. Results of the modal analysis.

\begin{tabular}{ccc}
\hline Mode & Frequency $\mathbf{( H z )}$ & Period (s) \\
\hline 1 & 0.391 & 2.554 \\
2 & 0.392 & 2.552 \\
3 & 0.493 & 2.026 \\
4 & 2.952 & 0.339 \\
5 & 3.394 & 0.295 \\
6 & 3.447 & 0.290 \\
\hline
\end{tabular}


Finally, a non-linear time history analysis was carried out applying, at the base of the structure, the horizontal acceleration time histories recorded by the sensors A01 and A03 during the 30 October 2016 Norcia earthquake.

For this purpose, a non-linear constitutive law was assumed for the hysteretic isolators that simulate the elastomeric devices. It is represented by Equation (4) and was approximated by a trilinear curve (Figure 20). The approximation was made to match Equation (4) in the range of small shear strain (0-0.03), which was of interest for the observed results during Norcia earthquake.

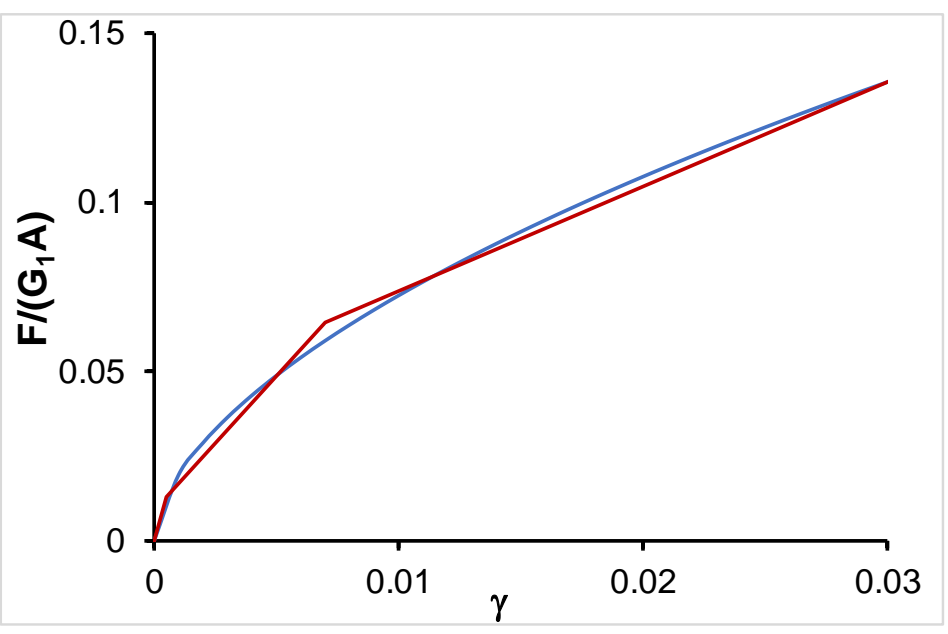

Figure 20. The non-linear relationship between force and shear strain for the elastomeric isolators, which accounts for the aging effects, approximated by a trilinear curve.

Sliding devices were modelled using sliding bearings having a very high initial stiffness, able to simulate the presence of a static friction, and a dynamic friction factor of $2 \%$, slightly amplified with reference to the initial one. The chosen increased stiffness of HDRBs and friction factor of SDs allowed to optimize the correspondence between experimental and numerical results. Both these assumptions can be justified as effects of the aging [31,32].

The results of the dynamic numerical analysis were compared to the seismic behavior observed during the Norcia earthquake. The good agreement between the acceleration time histories is apparent (Figure 21). Little discrepancies in terms of amplitudes can be attributed to a little lower stiffness of the numerical model with respect to the real structure. For the same reason the numerical displacement peaks are a little higher than those recorded during the earthquake (Figure 22). However, the frequency content of the recordings obtained during the event is well reproduced by the numerical model, as both the acceleration and displacement time histories show.

As already said, some crack patterns were observed on the partition walls of the first floor after the main event of 30 October 2016. In order to investigate this aspect, the relative displacements between the lower and upper beams were analyzed. It can be seen that an excursion greater than $2.0 \mathrm{~mm}$ around the value under vertical loads with a high frequency content, which occurred during the quake, can justify the cracks (Figure 23). 


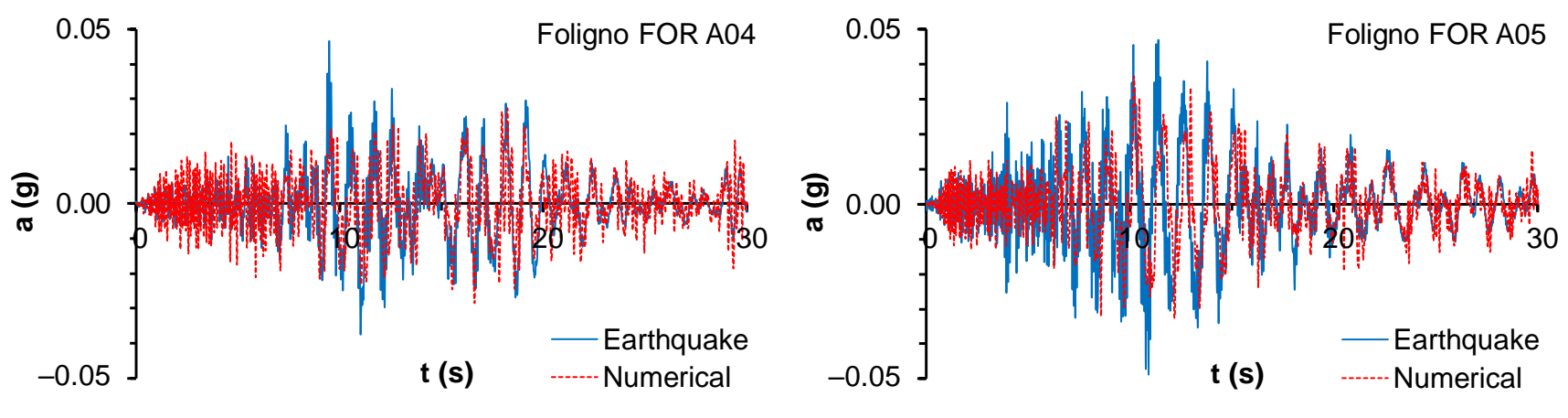

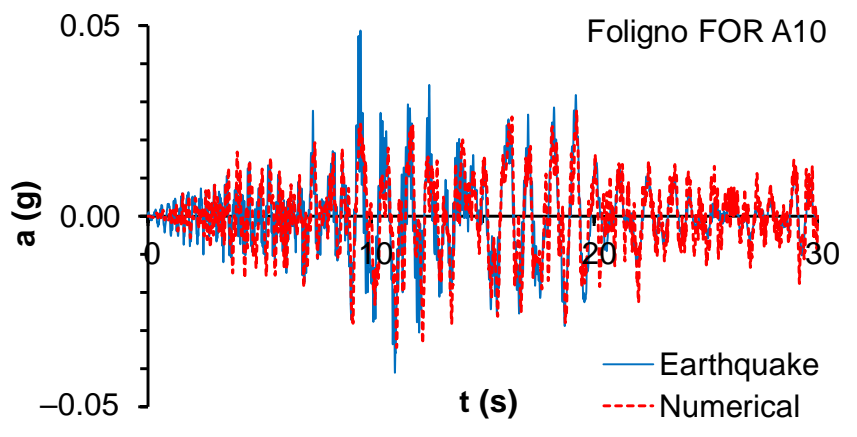

(a)

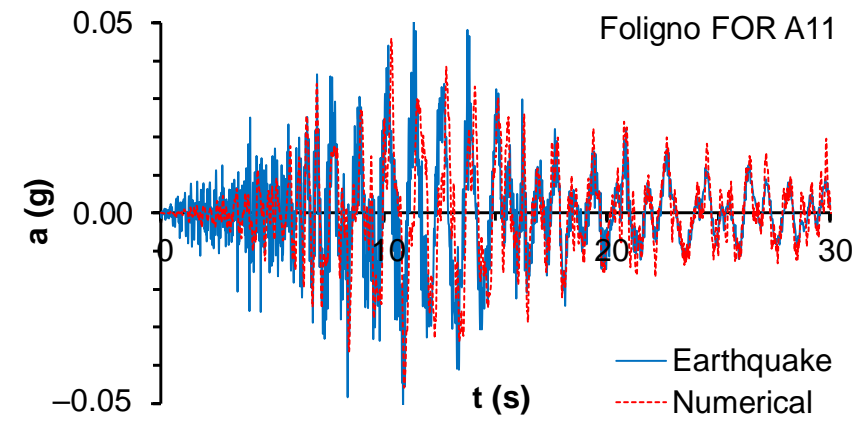

(b)

Figure 21. Comparison between the earthquake and numerical accelerations (a) in $\mathrm{x}$ direction and (b) in y direction.

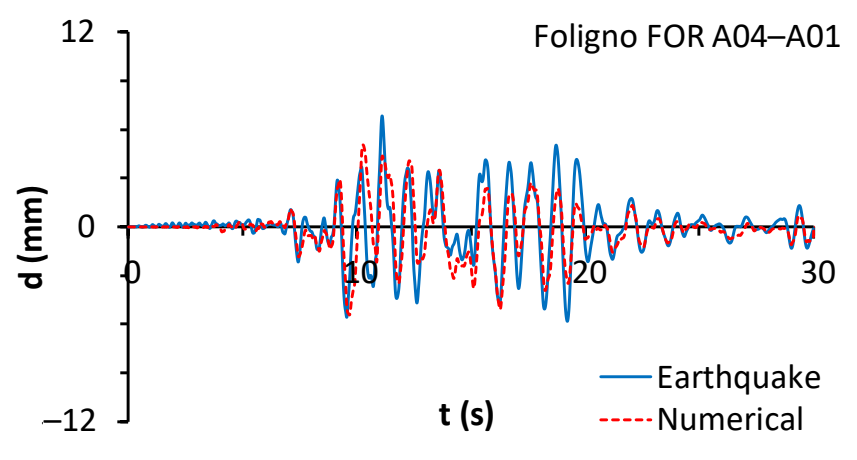

(a)

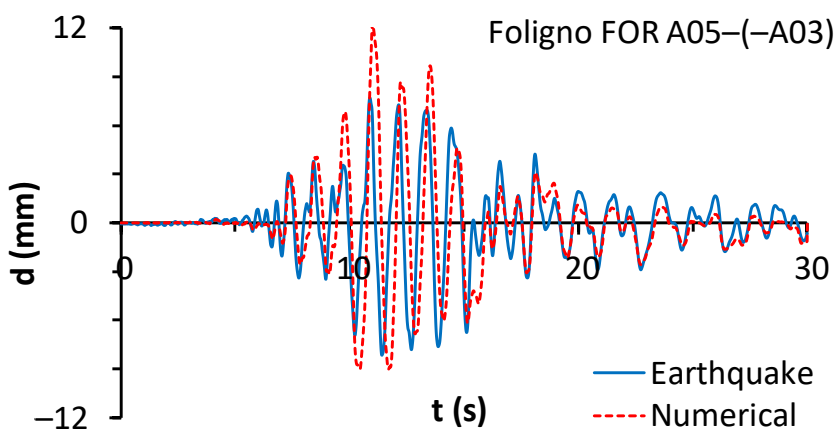

(b)

Figure 22. Comparison between the earthquake and numerical relative displacements between L1 and $\mathrm{LO},(\mathbf{a})$ in $\mathrm{x}$ direction and $(\mathbf{b})$ in $\mathrm{y}$ direction.

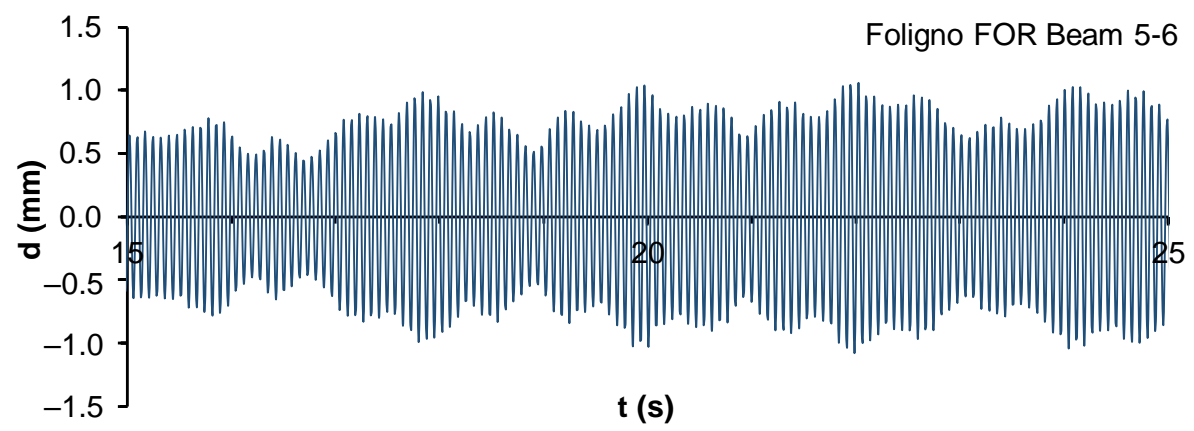

Figure 23. Relative displacement between the beams 5-6 of the first floor and of L1 in vertical direction. 


\section{Conclusions}

The behavior of a reinforced concrete building, seismically isolated with high damping rubber bearing (HDRB) and sliding devices (SD), observed during the most important events of the seismic sequence that struck central Italy from August 2016 to January 2017, was analyzed. All the events had quite low effects at the site due to the large epicenter distances; therefore, the isolation system was not always put into action during the events or showed very low displacements. However, small cracks were observed after the main event in some partition walls of the building. This occurrence did not affect the seismic protection of the structure through seismic isolation.

A detailed analysis of the recorded behavior during the main event of 30 October 2016 was first shown. Then, the effects of a number of selected events were analyzed and compared. Finally, a suitable finite element model was set up, in which a non-linear model for the elastomeric isolators, based on previous experimental data, and a friction model for the sliders were assumed. The model, first validated comparing the numerical and experimental responses at the sensor locations in terms of accelerations and displacements obtained during the main event, was used to interpret the experimental behavior.

The main results can be summarized as follows:

1. The resonance frequencies varied significantly with the energy at the site of the building and approached to the resonance frequencies of the superstructure for the lowest energy events.

2. As a result, there was no suitable decoupling of motion in some cases. This occurrence must be accounted for in the design of the isolation system and to evaluate the seismic actions in the superstructure.

3. The contribution of sliding devices was very important for the onset of motion under low energy earthquake. Actually, the isolation system was not put in action under very low energy events but only when the maximum friction forces in the sliding devices were not sufficient to face the seismic actions.

4. The contribution of the sliding devices significantly influenced the amplitude of vibrations and damping.

5. The analysis of the relative vertical displacements between the beams around the damaged partition walls pointed out vibrations at high frequency and amplitudes greater than $2.0 \mathrm{~mm}$. These acted in conjunction with the horizontal vibrations and can justify the observed small cracks.

In order to verify all these aspects, non-linear analyses should be recommended to evaluate the effects of earthquakes with different energy at the site. The analyses should account for the non-linear behavior of the elastomeric isolators, with particular reference to the behavior at very small shear strain, and of the sliding devices, with particular reference to the static and dynamic frictions. These analyses would be of fundamental importance to verify a suitable decoupling of motion and a correct working of an isolation system also under low energy earthquakes.

Author Contributions: Conceptualization, A.S., G.B., P.C., C.O., F.S. (Fernando Saitta) and F.S. (Federico Scafati); methodology, A.S., G.B., P.C., C.O., F.S. (Fernando Saitta) and F.S. (Federico Scafati); software, A.S., G.B., P.C., C.O., F.S. (Fernando Saitta) and F.S. (Federico Scafati); validation, A.S., G.B., P.C., C.O., F.S. (Fernando Saitta) and F.S. (Federico Scafati); formal analysis, A.S., G.B., P.C., C.O., F.S (Fernando Saitta) and F.S. (Federico Scafati); investigation, A.S., G.B., P.C., C.O., F.S. (Fernando Saitta) and F.S. (Federico Scafati); resources, A.S., G.B., P.C., C.O., F.S. (Fernando Saitta) and F.S. (Federico Scafati); data curation, A.S., G.B., P.C., C.O., F.S. (Fernando Saitta) and F.S. (Federico Scafati); writingoriginal draft preparation, A.S., G.B., P.C., C.O., F.S. (Fernando Saitta) and F.S. (Federico Scafati); writing-review and editing, A.S., G.B., P.C., C.O., F.S. (Fernando Saitta) and F.S. (Federico Scafati); visualization, A.S., G.B., P.C., C.O., F.S. (Fernando Saitta) and F.S. (Federico Scafati); supervision, A.S., G.B., P.C., C.O., F.S. (Fernando Saitta) and F.S. (Federico Scafati); project administration, G.B. and P.C.; funding acquisition, G.B. and P.C. All authors have read and agreed to the published version of the manuscript. 
Funding: The research work leading to this paper has been developed in the framework of a research project organized and funded by ENEA and Umbria Region.

Conflicts of Interest: The authors declare no conflict of interest regarding the publication of this paper.

\section{References}

1. Clemente, P. Seismic isolation: Past, present and the importance of SHM for the future. J. Civ. Struct. Heal. Monit. 2017, 7, 217-231. [CrossRef]

2. Calvi, P.M.; Calvi, G.M. Historical development of friction-based seismic isolation systems. Soil Dyn. Earthq. Eng. 2018, 106, 14-30. [CrossRef]

3. Naeim, F.; Kelly, J.M. Design of Seismic Isolated Structures: From Theory to Practice; John Wiley \& Sons Inc.: Hoboken, NJ, USA, 1999. [CrossRef]

4. $\quad$ Skinner, R.I.; Robinson, W.H.; McVerry, G.H. An introduction to Seismic Isolation. DSIR Physical Sciences; John Wiley \& Sons Inc.: Wellington, New Zealand, 1993.

5. Clemente, P.; Martelli, A. Seismically isolated buildings in Italy: State-of-the-art review and applications. Soil Dyn. Earthq. Eng. 2019, 119, 471-487. [CrossRef]

6. Bongiovanni, G.; Buffarini, G.; Clemente., P.; Saitta, F.; Tripepi, C. Retrofit of existing buildings with seismic isolation: Design issues and applications. In Proceedings of the 16th World Conference on Seismic Isolation, Energy Dissipation and Active Vibration Control of Structures, 16WCSI, St. Petersburg, FL, USA, 1-6 July 2019; pp. 111-122. [CrossRef]

7. Saitta, F.; Clemente, P.; Buffarini, G.; Bongiovanni, G. Vulnerability Analysis and Seismic Retrofit of a Strategic Building. J. Perform. Constr. Facil. 2017, 31, 04016085. [CrossRef]

8. Çelebi, M. Successful performance of a base-isolated hospital buildings during the 17 January 1995 Northridge earthquake. Struct. Des. Tall Build. 1996, 5, 95-109. [CrossRef]

9. Nagarajaiah, S.; Xiaohong, S. Response of Base-Isolated USC Hospital Building in Northridge Earthquake. J. Struct. Eng. 2000, 126, 1177-1186. [CrossRef]

10. Nagarajaiah, S.; Sun, X. Base-Isolated FCC Building: Impact Response in Northridge Earthquake. J. Struct. Eng. 2001, 127, 1063-1075. [CrossRef]

11. Loh, C.-H.; Weng, J.-H.; Chen, C.-H.; Lu, K.-C. System identification of mid-story isolation building using both ambient and earthquake response data. Struct. Control. Health Monit. 2011, 20, 139-155. [CrossRef]

12. Matsuda, K.; Kasai, K.; Yamagiwa, H.; Sato, D. Responses of base-isolated buildings in Tokyo during the 2011 Great East Japan Earthquake. In Proceedings of the 15th World Conf. on Earthquake Engineering (15WCEE), Lisbon, Portugal, 24-28 September 2012.

13. Siringoringo, D.M.; Fujino, Y. Seismic response analyses of an asymmetric base-isolated building during the 2011 Great East Japan (Tohoku) Earthquake. Struct. Control. Health Monit. 2014, 22, 71-90. [CrossRef]

14. Zhou, F.L.; Tan, P.; Heisha, W.; Huan, X.Y. Progress and application of seismic isolation, energy dissipation and control in civil and industrial structures and design codes in China. In Proceedings of the 14th World Conf. on Seismic Isolation, Energy Dissipation and Active Vibration Control of Structures (14WCSI), San Diego, CA, USA, 9-11 September 2015.

15. Zhou, C.; Chase, J.G.; Rodgers, G.W.; Kuang, A.; Gutschmidt, S.; Xu, C. Performance evaluation of CWH base isolated building during two major earthquakes in Christchurch. Bull. N. Z. Soc. Earthq. Eng. 2015, 48, 264-273. [CrossRef]

16. Takayama, M.; Morita, K. Observed performance of seismically isolated buildings during 2016 Kumamoto Earthquake in Japan. In Proceedings of the 17th World Conference on Earthquake Engineering (17WCEE), Sendai, Japan, 28 September-2 October 2021. Paper $\mathrm{N}^{\circ} \mathrm{C} 000234$.

17. Martelli, A.; Clemente, P.; De Stefano, A.; Forni, M.; Salvatori, A. Recent Development and Application of Seismic Isolation and Energy Dissipation and Conditions for Their Correct Use. In Geotechnical, Geological and Earthquake Engineering; Springer: Berlin/Heidelberg, Germany, 2014; Volume 34, pp. 449-488. [CrossRef]

18. Clemente, P.; Buffarini, G. Base isolation: Design and optimization criteria. SIAPS 2010, 1, 17-40. [CrossRef]

19. Clemente, P.; Bontempi, F.; Boccamazzo, A. Seismic Isolation in Masonry Buildings: Technological and economic issues. In Brick and Block Masonry: Trends, Innovation and Challenges, Proceedings of the 6th International Conference (IB2MAC), Padua, Italy, 26-30 Jun 2016; Modena, C., da Porto, F., Valluzzi, M.R., Eds.; Taylor \& Francis Group: London, UK, 2016; pp. 2207-2215. ISBN 978-1-138-02999-6.

20. Tripepi, C.; Clemente, P. Graphic Procedure for the Optimum Design of Elastomeric Isolators. Pract. Period. Struct. Des. Constr. 2021, 26, 04020058. [CrossRef]

21. Saitta, F.; Clemente, P.; Buffarini, G.; Bongiovanni, G.; Salvatori, A.; Grossi, C. Base Isolation of Buildings with Curved Surface Sliders: Basic Design Criteria and Critical Issues. Adv. Civ. Eng. 2018, 2018, 1-14. [CrossRef]

22. Clemente, P.; Bongiovanni, G.; Buffarini, G.; Saitta, F.; Scafati, F. Monitored Seismic Behavior of Base Isolated Buildings in Italy. In Seismic Structural Health Monitoring, Springer Tracts in Civil Engineering; Limongelli, M., Celebi, M., Eds.; Springer: Cham, Switzerland, 2019; pp. 115-137. [CrossRef]

23. Ormando, C.; Clemente, P.; Ianniruberto, U.; Scafati, F. Onset of Motion of Curved Surface Sliders Used in Seismic-Isolation Systems. Pract. Period. Struct. Des. Constr. 2021, 26, 04021015. [CrossRef] 
24. Scafati, F.; Ormando, C.; Clemente, P.; Bongiovanni, G. Observed behavior of buildings seismically isolated with CSSs under a low energy earthquake. J. Civ. Struct. Health Monit. 2021, 1-19. [CrossRef]

25. Clemente, P.; Bongiovanni, G.; Buffarini, G.; Saitta, F.; Castellano, M.G.; Scafati, F. Effectiveness of HDRB isolation systems under low energy earthquakes. Soil Dyn. Earthq. Eng. 2019, 118, 207-220. [CrossRef]

26. Salvatori, A.; Di Cicco, A.; Clemente, P. Seismic monitoring of buildings with base isolation. In Computational Methods in Structural Dynamics and Earthquake Engineering, Proceedings of the 7th ECCOMAS Thematic Conference, COMPDYN 2019, Crete Island, Greece, 24-26 June 2019; Papadrakakis, M., Fragiadakis, M., Eds.; Institute for Structural Analysis and Antiseismic Research, National Technical University of Athens (NTUA): Athens, Greece, 2019; ID 19221; Available online: https:/ /2019.compdyn.org/ proceedings / (accessed on 19 January 2022).

27. Clemente, P.; Di Cicco, A.; Saitta, F.; Salvatori, A. Seismic Behavior of Base Isolated Civil Protection Operative Center in Foligno, Italy. J. Perform. Constr. Facil. 2021, 35, 04021027. [CrossRef]

28. Presidency of the Council of Ministers. Ordinance OPCM 3274/2003. Primi Elementi in Materia di Criteri Generali per la Classificazione Sismica del Territorio Nazionale e di Normative Tecniche per le Costruzioni in Zona Sismica; G.U. 08/05/2003, Supplemento Ordinario 72; Istituto Poligrafico e Zecca dello Stato: Rome, Italy, 2003.

29. Arias, A. Arias, A. A measure of earthquake intensity. In Seismic Design for Nuclear Power Plants; Hansen, R.J., Ed.; MIT Press: Cambridge, UK, 1970; pp. 438-483.

30. Dabnath, L.; Shah, F. Wavelet Transform and Their Application; Springer Science: Berlin/Heidelberg, Germany, 2002.

31. McVitty, W.J.; Constantinou, M.C. Property Modification Factors for Seismic Isolators: Design Guidance for Buildings; MCEER Report No. 15-0005; University at Buffalo, State University of New York: Buffalo, NY, USA, 2015.

32. Mazza, F. Effects of the long-term behaviour of isolation devices on the seismic response of base-isolated buildings. Struct. Control. Health Monit. 2019, 26, e2331. [CrossRef] 